\title{
Aprendizagem intercultural na formação de professores de Alemão como Língua Estrangeira no Brasil
}

Intercultural Learning in the Training of Teachers of German as a Foreign Language in Brazil

Maria Monteiro*

\begin{abstract}
A reflection on the goal of intercultural learning does not seem to be present in Brazilian publications, especially in the area of German as a Foreign Language. Although intercultural learning is the subject of many papers, contents and objectives seem still to be determined by courseware of German publishers, and this is reflected in the training of future teachers. The solution would be a consistent and systematic integration, since the beginning of the academic studies, of the specific content related to German as a Foreign Language in the undergraduate programs in German, through a real interdisciplinarity of the areas of Language and Literature and the Humanities.
\end{abstract}

Keywords: Intercultural Learning; German as a Foreign Language, Teachers Training;

Resumo: Uma reflexão básica sobre o objetivo da aprendizagem intercultural parece ainda não estar presente nas publicações brasileiras, principalmente na área de Alemão como Língua Estrangeira. Embora a aprendizagem intercultural seja tema de muitos trabalhos da área, o conteúdo e os objetivos parecem ainda ser fixados pelo material didático mais recente do catálogo das editoras alemãs, e isso se reflete na formação dos futuros professores. A solução seria uma integração consequente e sistemática, desde o início do curso, dos conteúdos específicos relativos ao Alemão como Língua Estrangeira no Curso universitário de alemão, através de uma real interdisciplinaridade entre as áreas de Letras e de Ciências Humanas.

Palavras-chave: Aprendizagem intercultural; Alemão como Língua Estrangeira; formação de professores

\footnotetext{
* Prof. Adjunto, Faculdade de Letras, Universidade Federal do Rio de Janeiro. Email: liamon@ @entroin.com.br O presente artigo foi publicado, em alemão, em SCHMENK/WÜRFFEL 2011. Obtida a autorização para publicação em português, foi feita a tradução por Valéria Sabrina Pereira e revisada pela autora do artigo.
} 
Monteiro, M. - Aprendizagem intercultural

\section{Introdução}

Quando se observam as publicações brasileiras atuais sobre a "aprendizagem intercultural" nas aulas de língua estrangeira, não é difícil reconhecer que se faz ausente uma reflexão básica sobre o objetivo da aprendizagem. Observa-se que, depois de praticamente vinte anos de controvérsia teórica, ainda, ou mais uma vez, não está de todo claro o que se deve aprender - de forma que aquilo sobre o que Dietmar Rösler já havia alertado em 1993 se tornou realidade:

Conceitos que são introduzidos na discussão para chamar a atenção para o que até então foi negligenciado tornam-se independentes, são utilizados de maneira inflacionária, perdem sua assertividade e, podem, após algum tempo, até contribuir para que outros componentes que integram a aprendizagem de língua estrangeira sejam então suprimidos da discussão (RÖSLER 1993: 90) ${ }^{1}$.

No âmbito da formação universitária de professores e docentes de alemão como língua estrangeira, falta um debate disciplinar sobre a "abordagem" intercultural, o qual deve estar associado às estruturas existentes, pois, apesar de os objetivos diferentes nos currículos dos estados permitirem uma variação muito grande nos tipos de formação universitária que oferecem, há, quase sempre, um denominador comum entre os estudantes iniciantes: não dispor de conhecimentos de alemão no começo do curso (cf. MonTEIRo 2010). Isso faz com que os primeiros anos sejam necessariamente dedicados ao aprendizado da língua alemã. Além da aquisição da língua, as disciplinas oferecidas nos cursos atuais são de natureza germanística, ou seja, a ênfase é dada à Língua Alemã, Literatura Alemã e Tradução. Os futuros professores de Alemão como Língua Estrangeira, no melhor dos cenários, somente têm contato com questões de prática de ensino, de didática e do método específico da disciplina em um ano complementar de licenciatura, no qual a "aprendizagem intercultural" é, quando tratada, tematizada apenas marginalmente.

\footnotetext{
1 "Konzepte, die in der Diskussion eingeführt werden, um auf bisher Vernachlässigtes aufmerksam zu machen, verselbständigen sich, werden inflationär gebraucht, verlieren ihre Trennschärfe und tragen nach einiger Zeit eventuell selbst dazu bei, nun andere integrale Bestandsteile des Fremdsprachenlernens aus der Diskussion zu verdrängen."
} 
Além do duplo mestrado (Doppel-Master-Studiengang) ${ }^{2}$ introduzido no ano de 2009 em Curitiba (em cooperação com o Herder-Institut Leipzig), não há nas universidades brasileiras qualquer programa de mestrado ou doutorado em ensino de alemão como língua estrangeira. Mesmo na pós-graduação da maior e mais renomada universidade do Brasil, a Universidade de São Paulo (USP), a "Área de Alemão" é mais propriamente "responsável pela formação de pesquisadores de língua e literatura do que pela formação de professores de alemão como língua estrangeira propriamente ditos"3 (NOMURA 2001:105).

Uma vez que mal há espaço para uma discussão acadêmica sobre o conceito de aprendizagem intercultural na área universitária aqui brevemente esboçada, a maioria das publicações discutidas neste artigo refere-se a observações feitas na prática comunicativa. Infelizmente, é frequente não se diferenciar entre a formação universitária de futuros professores de alemão como língua estrangeira e os cursos de língua que atuam comercialmente. No centro das observações a seguir está, em primeiro lugar, o que deve ser compreendido pelo conceito "intercultural" e, em seguida, se e até que ponto os materiais didáticos disponíveis podem contribuir para o aprendizado intercultural.

\section{Sobre o adjetivo "intercultural"}

A maioria dos trabalhos que se ocupa da aprendizagem intercultural em aulas de língua estrangeira procura criar uma ponte entre as disposições formuladas nas políticas educacionais brasileiras (quase que exclusivamente com referência às aulas de inglês nas escolas) e as considerações teóricas sobre o conceito "intercultural". Assim, costuma-se perder a oportunidade de definir como se deve entender exatamente esse conceito.

Em vez disso, parece haver outras perguntas mais importantes, como, por exemplo, “de quanto conhecimento cultural (Landeskunde) necessita o aluno?” quando ele vive tão longe do país da língua alvo, como nesta consideração:

\footnotetext{
${ }^{2}$ Nesta modalidade, aqueles que concluem o Curso recebem o diploma de Mestrado brasileiro e o Master alemão.

3 “zuständig für die Ausbildung von Sprach- und Literaturforschern als für die eigentliche Ausbildung von DaFLehrern.”
} 
Monteiro, M. - Aprendizagem intercultural

A localização geográfica do Brasil e a situação social da maioria dos estudantes universitários fazem com que uma viagem ao país da língua alvo, quando possível, seja apenas um projeto a longo prazo. Isso leva ao questionamento sobre de quão útil é um estudo com detalhes sobre Landeskunde e a cultura cotidiana dos países da língua alvo nas aulas para iniciantes. ${ }^{4}$ (BOHUNOVSKY/BOLOGNINI 2006: 1)

As autoras aqui citadas representam a linguística crítica aplicada que atualmente está em voga no Brasil, a qual também norteia a formulação dos Parâmetros Curriculares Nacionais e a Reorientação Curricular do Estado do Rio de Janeiro, no que diz respeito às aulas de língua estrangeira. No mesmo artigo, elas criticam o fato de "que os métodos e materiais didáticos comumente utilizados em aulas de língua estrangeira não estão adaptados à realidade dos estudantes universitários brasileiros" ${ }^{\not 5}$ e se referem, mais uma vez, às aulas escolares de inglês, citando uma frase de um grande jornal: "Não leva a nada pedir que crianças na periferia de São Paulo repitam um diálogo de alguém que acaba de chegar ao aeroporto de Londres"6 ( $O$ Estado de São Paulo, 2 de maio de 2005). Mas qual seria a alternativa? Se procurarmos diferenciar e separar o aprendizado de língua e de cultura, serão concebíveis, no futuro (e novamente!), livros didáticos nos quais sejam predominantes situações artificialmente construídas, como, por exemplo, crianças da periferia de São Paulo que esclarecem uma para a outra, em inglês, o caminho para a agência de correio. Outra passagem do mesmo artigo indica como as autoras concebem a aprendizagem intercultural:

Os materiais didáticos utilizados também no Brasil em aulas de alemão como língua estrangeira foram publicados na Alemanha sem diferenciação para o mercado mundial e, por isso, não podem de forma alguma estar de acordo com aspectos culturais contrastivos de dois âmbitos culturais diferentes. Em nossa opinião, justamente isso seria necessário para uma aula de Landeskunde que promova a competência intercultural, principalmente em um país como o Brasil. ${ }^{7}$ (BOHUNOVSKY/BOLOGNINI 2006: 4).

\footnotetext{
4 "Die geographische Lage Brasiliens und die soziale Situation der meisten StudentInnen lassen eine Reise ins Land der Zielsprache ein, wenn überhaupt, nur sehr langfristiges Projekt werden. Das führt zur Frage, wie sinnvoll eine Auseinandersetzung mit Details der Landeskunde und der Alltagskultur der Zielsprachenländer im AnfängerInnenunterricht ist."

5 “dass die im Fremdsprachenunterricht üblicherweise verwendeten Methoden und Lehrmaterialien nicht an die Realität der meisten brasilianischen StudentInnen angepasst sind"

6 "Es bringt nichts, in der Peripherie São Paulos die Kinder zu bitten, einen Dialog von jemandem zu wiederholen, der gerade am Londoner Flughafen ankommt"

7 "Die auch in Brasilien im DaF-Unterricht verwendeten Lehrmaterialien wurden in Deutschland undifferenziert für den Weltmarkt veröffentlicht und können daher auf kulturkontrastive Aspekte zweier spezieller Kulturkreise gar nicht eingehen. Gerade das wäre aber unserer Meinung nach für einen die interkulturelle Kompetenz fördernden Landeskundeunterricht notwendig, vor allem in einem Land wie Brasilien."
} 
Monteiro, M. - Aprendizagem intercultural

Se, por um lado, compartilho da reserva contra a adoção acrítica dos mais novos livros didáticos, por outro, o subsequente trato negligente com a terminologia não pode ser aceito sem comentários: as autoras não especificam em nenhum lugar o que entendem por "competência intercultural" e, para fomentá-la, advogam seriamente a favor de maior contraste cultural na aula de Landeskunde. O que é de fato questionável aqui é a ligação automática (para não dizer automatizada) entre Landeskunde e a aprendizagem intercultural, pois:

Quanto mais o debate sobre os aspectos interculturais do aprendizado de língua estrangeira se limitar à Landeskunde e demonstrar a tendência de desenvolver uma espécie de 'curso básico de antropologia', menos se pode falar de uma abordagem intercultural para a aprendizagem de língua estrangeira. ${ }^{8}$ (RÖSLER 1994: 109).

Certamente não se alcança a aprendizagem intercultural através de exercícios contrastivos direcionados, nos quais grupos (construídos) com diferentes manifestações de crença, pensamento, percepção, sentimento, verbalizações e ações firmadas sob o conceito de “cultura" são descritos e dissecados; ela também não termina com a tentativa de superar estereótipos.

A ideia de que estereótipos não podem ser simplesmente desconstruídos, mas que devem ser tratados no percurso em direção a uma competência intercultural, difundiu-se amplamente. BoHUNOVSKY (2009: 3) escreve, em outro artigo:

\begin{abstract}
Por outro lado, ela [a competência intercultural] pode conduzir à preservação ou até mesmo ao fortalecimento da polarização, ou, melhor dizendo, a uma compreensão dicotômica de uma cultura 'própria' e uma 'estrangeira'. BREDELLA e DELANOY, por exemplo, veem o perigo de uma 'hermenêutica comparatista' em uma aula de língua estrangeira comparativa no fato de que o 'outro' possa ser segregado e estigmatizado como 'totalmente diferente', 'com o qual não se tem nada em comum'"(BREDELLA/ DELANOY 1999: 14). Com isso, estereótipos nacionais podem até mesmo ser consolidados - mas justamente estes são vistos como impedimento para a obtenção da "competência intercultural".
\end{abstract}

\footnotetext{
8 “Je stärker sich die Auseinandersetzung mit interkulturellen Aspekten des FL auf die Landeskunde beschränkt und Tendenzen zeigt, eine Art , anthropologischer Grundkurs' zu entwickeln, desto weniger kann man von einem interkulturellen Ansatz zum FL reden”

9 “Andererseits kann er aber auch zu einer Bewahrung oder sogar Verstärkung der Polarisierung, bzw. zu einem dichotonen Verständnis von 'eigener' und 'fremder' Kultur führen. Bredella und Delanoy sehen beispielsweise die Gefahr einer 'komparatistischen Hermeneutik' im interkulturellen Fremdsprachenunterricht darin, dass der 'Andere' als der 'ganz Andere', 'mit dem man nicht gemein hat' ausgegrenzt und stigmatisiert wird (Bredella \& Delanoy 1999: 14). Nationale Stereotypen können somit sogar gefestigt werden - gerade diese werden aber meist als Hindernis zur Erreichung 'interkultureller Kompetenz’ angesehen.”
} 


\section{Monteiro, M. - Aprendizagem intercultural}

De fato, espera-se obter, em muitas pesquisas contrastivas, um "ser diferente" culturalmente determinado, nas quais algumas dicotomias são construídas com precisão científica. Mas os seres humanos são, em primeiro lugar, indivíduos dotados de consciência, que podem se ajustar a novas situações e que podem aprender a se orientar em contextos que lhe são estranhos, e essa capacidade não teve início apenas a partir da tão falada era da migração mundial e da globalização. Além disso, essa "aprendizagem intercultural” é compreendida por mim, em consonância com GHOBEYSHI/KOREIK (2003: 352), como "o desenvolvimento de competência de atuação em situações de contato intercultural com base em uma habilidade de percepção e aquisição de significados estrangeiros em diferentes sistemas de símbolos verbais e não verbais, com o objetivo de poder reconhecer e superar as percepções marcadas pela própria cultura [...]"10. Sabe-se que o grau da "marca da própria cultura" varia de indivíduo para indivíduo e não é universal, assim como o fato de tanto a aprendizagem de línguas quanto a aprendizagem intercultural serem processos individuais. Partindo desse aspecto, considero comparações culturais como "o que é típico de..." como contraprodutivas, quando não se alude explicitamente ao problema da determinação e da seletividade da percepção, dos pontos de vista e das normas de comportamento próprios, de cada indivíduo.

O problema da representação dicotômica é reforçado também pelo material didático. Evidentemente, não há tema que não possa ser abordado comunicativa e contrastivamente. A pergunta que costuma ser feita em livros didáticos, "como é na sua terra natal?" ou "imagine essa situação também na sua terra natal", pode ser útil para, em um primeiro momento, conscientizar o aprendiz sobre diferenças existentes e questionar a sua obviedade. Contudo, com frequência, circunstâncias complexas costumam ser reduzidas a meras superficialidades de fácil apreensão, as quais não possibilitam a compreensão da "outra cultura" como dinâmica, aberta e eclética.

\section{A eterna discussão sobre o material didático}

\footnotetext{
10 "Entwicklung von Handlungskompetenz für interkulturelle Kontaktsituationen auf der Basis einer geschulten Wahrnehmungs- und Aneignungsfähigkeit fremder Bedeutungen in unterschiedlichen verbalen und nonverbalen Zeichensystemen, dies mit dem Ziel, die Grenzen der eigenkulturell geprägten Wahrnehmung erkennen und überschreiten zu können (...)"
} 
As decisões mais importantes sobre o conteúdo e o método são, geralmente, deixadas a cargo do material didático, sendo praticamente uma tradição que seja "adotado" o material didático escolhido entre obras oferecidas nos mais novos catálogos das editoras especializadas. Assim, são adotadas concepções de aula que não são adequadas ao grupo específico de alunos, mas que são vendidas como "progressistas e modernas" (vide RöSLER 1993: 89). Essa atitude não surge apenas do lado brasileiro, sendo também forte e frequentemente explicitada pelos alemães, muitas vezes através de órgãos oficiais como o Goethe-Institut: os materiais didáticos publicados mais recentemente na Alemanha devem (com a justificativa de que seriam mais adequados para uma aula nos tempos atuais) ser introduzidos também nas universidades, sem levar em consideração as especificidades do grupo de alunos. As boas intenções que estão por trás dessa atitude não podem desmentir os fatos: a maioria dos materiais didáticos comercializados sob o logo estrelado da Europa se diferencia apenas marginalmente dos antigos materiais didáticos que tiveram um ajuste posterior às diretrizes do Quadro Comum Europeu de Referência.

BOHUNOVSKY E BoLOGNINI (2006) criticam, na tradição da linguística crítica aplicada, o "idílio de cartões postais" nas obras didáticas importadas, que supostamente podem "levar, em um país como o Brasil, não apenas a uma intensificação de uma imagem (muitas vezes) exageradamente positiva do país da língua alvo, mas também do próprio sentimento de inferioridade". ${ }^{11}$ Do meu ponto de vista, isso não apenas é exagerado; tive, e tenho, em minha prática de sala de aula, experiências que comprovam o contrário. Os estudantes sabem que o mundo das obras didáticas é pintado em belas cores e formas. Mas, em geral, também não querem ser confrontados com problemas. No livro didático Eurolingua 3 (nova edição), surge, por exemplo, no primeiro capítulo, um texto sobre a alta taxa de desemprego em partes da Alemanha. O texto causou grande irritação nos estudantes porque estes não o compreenderam como uma representação objetiva de um problema social sério, mas como uma mensagem oculta ("Nós temos desempregados o suficiente, por favor, permaneçam em sua terra natal").

Tanto as obras didáticas mais novas quanto as mais antigas exigem dos professores que reconheçam os conteúdos culturais específicos implícitos, juntamente com os números, dados e fatos de Landeskunde transmitidos explicitamente e, ainda, que conscientizem seus

\footnotetext{
11 “in einem Land wie Brasilien also dazu führen [kann], nicht nur das (oft übertrieben) positive Bild des Zielsprachenlandes zu verstärken, sondern auch das eigene Minderwertigkeitsgefühl”
} 
Monteiro, M. - Aprendizagem intercultural

alunos sobre todas essas informações, verbalizando-as, contextualizando-as e discutindo-as da maneira que desejarem. Porém, aí temos um grande obstáculo: como a maioria dos docentes brasileiros tem uma formação germanística clássica ou literária, não possuem a formação necessária para coordenar esse processo de sensibilização com relação a elementos culturais específicos. Creio que esse problema só pode ser solucionado a longo prazo, através de uma integração consequente e sistemática, desde o início do curso, dos conteúdos específicos relativos ao Alemão como Língua Estrangeira no curso universitário de alemão.

\section{Desideratos na formação universitária de professores de alemão como língua estrangeira}

Para verificar se e até que ponto os estudantes foram familiarizados com os conceitos "cultura", "interculturalidade" e "aproximação intercultural" durante sua formação, foi feita uma pesquisa com estudantes do último semestre de 2010. Os resultados permitiram que se chegasse a conclusões tanto sobre o conhecimento dos estudantes quanto sobre o conteúdo das palavras-chave acima citadas.

O conceito "cultura" é definido de forma diversa pelos estudantes, por vezes como "a união entre costumes e lugares" ou como "tudo o que caracteriza um lugar como um determinado país, ou seja, todos os costumes, canções e danças, entre outros”, e, por outras vezes, como "hábitos de um determinado povo". Um estudante respondeu que "a cultura é composta por costumes e tradições de um povo e abrange conhecimentos e vivências de um indivíduo. Cada povo tem características típicas que o diferem dos outros”. Alguns estudantes veem as circunstâncias de forma um pouco diferenciada: "Eu acho que há características típicas. Mas é complexo e difícil refletir sobre isso. Quando se ignoram os estereótipos, creio que há tanto uma cultura tipicamente alemã como uma tipicamente brasileira por razões histórico-sociais". Ou: “Cultura é a união de tradições e costumes de um povo. É sua identidade e o modo como ela se diferencia de outros povos. Há algumas generalizações sobre todos os povos. Em toda generalização há um pouco de verdade. Se todo povo tem sua cultura e essa é a sua identidade, então algumas dessas qualidades vão caracterizar o povo. Mas não se podem considerar qualidades típicas que têm a ver com um caráter humano como 
Monteiro, M. - Aprendizagem intercultural

qualidades típicas de um povo. O ser humano é igual em toda parte. O que muda é em que ponto da latitude da Terra ele vive."

Os atributos evocados para o conceito de "cultura" são, em minha opinião, indícios de uma confusão: a cultura alemã típica "é pontual e organizada”, a brasileira, pelo contrário, é “impontual e desorganizada”. Outro estudante dá outra explicação: "Uma vez que a Alemanha é muito menor do que o Brasil é mais fácil definir a cultura alemã. Ela é mais sólida, mais definida e mais evidente, mesmo quando há diferenças internas. No Brasil, a cultura é híbrida, composta de inúmeros costumes que se diferenciam de região para região".

Como e de onde eles conhecem o conceito também não é claro. Um estudante afirma: "Sim, eu estudei um pouco isso. Aprendi que há muitas diferenças entre a nossa cultura e a alemã, mas nada que signifique maiores constrangimentos ou rejeições”. Outro afirma: "Eu tive um pouco de cultura nas aulas de literatura e algumas vezes nas aulas de alemão, algo sobre temas como comida, tempo etc."

Algo semelhante ocorre quando se trata do conceito "interculturalidade"; a maior parte das respostas inclui afirmações vagas ou até mesmo erradas: "intercultural significa o contato com diferentes culturas" ou "quando se aprende uma língua estrangeira, também se passa a conhecer a outra cultura e isso é interculturalidade". A resposta a seguir, referente à pergunta sobre o que intercultural significa, é muito reveladora: "Isso não está muito claro na minha cabeça."

Apesar de as respostas dos estudantes terem se mostrado completamente heterogêneas, fica claro que se entende por "intercultural" ou o contato entre duas ou mais culturas, ou a comparação de duas ou mais culturas. Pode-se dizer que os estudantes de fato pensam sobre o assunto, mas evidentemente nunca tiveram um debate sistemático sobre a terminologia: temas como sensibilização, marcas da própria cultura, exame mais profundo e ampliação da própria percepção ou visão de mundo não são mencionados. O conceito central "estereótipo" surge apenas uma vez.

A estereotipagem é observada mais de perto em uma pesquisa abrangente de GHOBEYSHI (2010). Em seu estudo, a autora pesquisou que imagem tinham da Alemanha 151 estudantes de germanística brasileiros em quatro grandes universidades federais e concluiu que, de forma geral, a percepção que têm da Alemanha e dos alemães coincide com aquela 
Monteiro, M. - Aprendizagem intercultural

que predominava na comunidade brasileira em geral (não universitária), segundo uma representativa pesquisa atual. Houve variações significativas apenas entre os estudantes que já estiveram alguma vez em um país de língua alemã. Sem poder comentar resultados específicos, vale a pena mencionar neste ponto o tipo de resposta dada à pergunta definitivamente problemática, e que também foi problematizada pelos alunos, para que discorressem sobre as diferenças entre a cultura alemã e a brasileira: 21,9\% dos estudantes de alemão não responderam absolutamente nada e pelo menos $14,6 \%$ criticaram a pergunta ou a rejeitaram. Comentários como "Há pessoas de todas as personalidades nos dois países", "Pergunta estranha", "Pessoas são diferentes e estereótipos são perigosos", "Não se pode generalizar", "Prefiro não comentar, pois uma vez que não conheço nenhum alemão pessoalmente ou estive na Alemanha, posso mencionar estereótipos" deixam claro que alguns dos alunos de germanística definitivamente já se ocuparam com a temática e se recusam a responder a perguntas que fortaleçam ainda mais os estereótipos.

\section{Comentários finais}

Como já havia sido mencionado no início, a disciplina "Alemão como Língua Estrangeira" está engatinhando no Brasil, e importantes conceitos como o da aprendizagem intercultural são, por isso, tratados nas aulas de forma muito distanciada de sua aplicação. Enquanto uma discussão acadêmica interna no Brasil sobre essa disciplina se fizer ausente, a formação de professores de alemão como língua estrangeira permanecerá focada em obras didáticas e dependente delas, já que, de fato, elas são, a princípio, um fator comercial e que pouco auxiliam os docentes a adentrarem os aspectos enumerados nesta contribuição.

Muitas das adversidades estão fora do nosso campo de influências, como, por exemplo, o fato de que, em algumas universidades, as disciplinas específicas da Licenciatura são ministradas na Faculdade de Pedagogia, sem que haja uma cooperação com a Faculdade de Ciências Humanas com o objetivo de promover uma conciliação melhor do conteúdo a ser ensinado. Não existe, portanto, no momento, uma garantia de que os futuros professores de Alemão como Língua Estrangeira tenham qualquer tipo de contato com aspectos da aprendizagem intercultural durante a graduação. 
Monteiro, M. - Aprendizagem intercultural

Mas, mesmo onde aspectos da aprendizagem intercultural foram tangencialmente tocados durante a formação, os resultados não são significantemente melhores. Através da “Landeskundização” (Landeskundisierung), o intercultural tornou-se “a 'nacionalização' do estrangeiro" "12, tendo como resultado que "a individualidade das experiências do estrangeiro e da identidade no exterior e no próprio país" foram suprimidas com maior vigor "do processo de aprendizagem" (RÖSLER 1993: 99). ${ }^{13}$

\section{Referências bibliográficas}

BoHUNOVSKY, Ruth. Landeskunde und Interkulturalität im DaF-Unterricht: "Schröder fica no Brasil" oder "Brasilien liegt in Deutschland" - ein Film von Zé do Rock. In:_Tagungsakten des VII. Brasilianischen Deutschlehrerkongresses / Ata do VII Congresso Brasileiro de Professores de Alemão, 2009. Disponível em: http://abrapa.org.br/congresso/ruth-bohunovsky.php. Acesso em: 12.09.2010.

Bohunovsky, Ruth; Bolognini, Carmen Zink. Deutsch für Brasilianer: Begegnungen mit dem Fremden als Vorbereitung für interkulturelle Kompetenz. Zeitschrift für Interkulturellen Fremdsprachenunterricht, Edmonton, 2006, v. 11, n. 1, p. 1-1 Disponível em: http://zif.spz.tudarmstadt.de/jg-10-3/beitrag/BohunovskyBolognini2.htm. Acesso em: 12.09.2010.

BREDELLA, Lothar; DELANOY, Werner. Interkultureller Fremdsprachenunterricht. Tübingen: Narr, 1999.

GHOBEYSHI, Silke. Das Deutschlandbild in Brasilien und Möglichkeiten seiner Behandlung. Projekt. Revista dos Professores de Alemão no Brasil (Zeitschrift der Deutschlehrer in Brasilien), 2009, Nr. 48, 15-19.

GHOBEYSHI, Silke; KoREIK, Uwe. Kultur(en), Konflik(e) und Unterricht(en). Info DaF (2003), 30,4, 352-364.

MonTEIRO, Maria. Deutsch als Fremdsprache in Lateinamerika am Beispiel Brasiliens. In: Bernt AHRENHOLZ \& Ingelore OOMEN-WELKE (Hrsg.): Deutsch als Fremdsprache.

Deutschunterricht in Theorie und Praxis (DTP), hg. v. W. Ulrich. Bd. 10. Baltmannsweiler:

Schneider Hohengehren, 2010.

MONTEIRO, MARIA. Interkulturelles Lernen in der Ausbildung von DaF-Lehrern in Brasilien. In: Barbara SCHMENK \& Nicola WÜRFFEL (eds.): Drei Schritte vor und manchmal auch sechs zurück. Internationale Perspektiven auf Entwicklungslinien im Bereich Deutsch als Fremdsprache. Tübingen: Narr Francke Attempto Verlag, 2011.

NOMURA, Masa. Deutschausbildung an der USP: ihre Rolle im Kontext des DaF-Unterrichts und in der Ausbildung von Sprachforschern. Cadernos de Letras (2001) 16, Heft 17, 105-110.

RÖSLER, Dietmar. Drei Gefahren für die Sprachlehrforschung im Bereich Deutsch als Fremdsprache: Konzentration auf prototypische Lernergruppen, globale Methodendiskussion Trivialisierung

\footnotetext{
12 “zur 'Nationalisierung' des Fremden"

13،“die Individualität von Fremdheits- und Identitätserfahrungen in der Fremde und im Eigenen noch stärker aus dem Lernprozeß."
}

Pandaemonium, São Paulo, v. 15, n. 20, Dez. /2012, p. $212-223$ - www.fflch.usp.br/dlm/alemao/pandaemoniumgermanicum 
Monteiro, M. - Aprendizagem intercultural

und Verselbständigung des Interkulturellen. Jahrbuch Deutsch als Fremdsprache (1993) 19, 77-99.

RÖSLER, Dietmar. Deutsch als Fremdsprache. Stuttgart: Metzler, 1994.

Recebido em 08/06//2012

Aprovado em 01/08/2012 